\title{
8.2 Математична модель сумарної вірогідності безвідмовної роботи робочого обладнання автогрейдера в процесі виконання робочих операцій
}

Значна доля відмов землерийно-транспортних машин (ЗТМ) викликана через вихід з ладу навісного обладнання [373]. При цьому, як свідчать дані [373, 374 та ін.], до 90\% відмов обумовлено швидким зносом ріжучих елементів робочих органів (РО). Унаслідок чого відбувається збільшення сили різання на 60-200\%, що в свою чергу, приводить до втрати продуктивності або до збільшення енерговитрат, а це зрештою, сприяє підвищенню собівартості розробки грунту. До того ж недостатній термін служби РО ЗТМ обумовлює необхідність постійної заміни ріжучих елементів, що передбачає значні матеріальні витрати.

Таким чином, експлуатаційні якості ЗТМ в значній мірі визначаються довговічністю їх РО. Тому актуальним завданням $є$ вибір головних чинників, які, в першу чергу, впливають на передчасну втрату працездатності ріжучих елементів 3ТМ.

Чинники, які впливають на процес зношування ріжучих елементів РО ЗТМ, умовно можуть бути розділені на чотири групи [373, 374, 375 та ін.]:

- фізико-механічні властивості грунтів, до яких відносяться питоме зчеплення, гранулометричний склад, щільність, вологість, кут внутрішньо-го тертя, питомий опір різанню грунтів, вміст кам'янистих включень різної міцності тощо;

- параметри взаємодії ріжучого інструменту з грунтом, а саме швидкість руху РО, тиск, відстань різання і переміщення грунтів, а також кут різання;

- технологічні і конструктивні параметри ріжучих елементів РО ЗТМ (механічні і хімічні властивості матеріалів, форми i розміри різальних елементів);

- рівень технічного обслуговування i ремонту (відновлення) РО (кваліфікацію обслуговуючого персоналу і якість проведення ремонтних робіт). 
Експлуатація 3ТМ відбувається в різних грунтових умовах, а окремі робочі операції відрізняються один від одного схемами додатка зовнішніх навантажень і по-різному формують навантаженість вузлів робочого устаткування. Одними 3 основних показників надійності РО ЗТМ є вірогідність безвідмовної роботи і pecypc.

Усе експлуатаційне вантаження РО ЗТМ можливо розкласти на складові, що класифікуються за характерними ознаками [373]. Формування навантаженості походить від нормального робочого вантаження, граничних очікуваних навантажень i граничного випадкового навантаження. Саме нормальне робоче навантаження визначає ресурс робочого устаткування ЗТМ.

Вірогідність безвідмовної роботи різального елементу ЗТМ, зокрема ножа автогрейдера, є мультиплікативною функцією вірогідностей [373, 374], залежних від наступних чинників:

- максимального навантаження на ніж автогрейдера при виконанні робочих операцій (плануванні);

- зносу робочої поверхні ножа в процесі виконання робочих операцій;

- циклічного (знакозмінного) навантаження на ніж;

- погрішності технології виготовлення ножа;

- погрішності монтування ножа при установці (зборці) тощо.

Грунтуючись на отриманих результатах досліджень надійності ЗТМ багатьох відомих учених Д.П. Волкова, Л.В. Назарова, В. В. Нічке, А.К. Рейши та ін., як основний критерій надійності була обрана сумарна вірогідність безвідмовної роботи різального елементу РО автогрейдера $[374,375]$

$$
P_{\Sigma}=P\left(P_{\text {дин }}\right) \cdot P\left(h_{\text {зн }}\right) \cdot P\left(P_{\text {зн }}\right) \cdot P_{\mathrm{T}} \cdot P_{\mathrm{M}},
$$

Дві останні вірогідності, залежної від погрішності виготовлення i монтування ножа, приймаємо рівні одиниці, тобто вважаємо, що різальний елемент виготовлено без яких-небудь погрішностей і встановлено ідеально на основному відвалі автогрейдера. 
Ймовірності $P\left(P_{\text {дин }}\right), P\left(h_{3 н}\right), P\left(P_{3 н}\right)$ взаємопов'язані між собою таким чином: при зносі робочої поверхні ножа на величину $h_{3 н}$ змінюється перетин ножа, а отже, і його несуча здатність. У свою чергу, від останньої залежить максимальне значення зусилля на кромці ножа, яке він може витримати. Від несучої здатності залежить також ймовірність $P\left(P_{\text {зн }}\right)$.

В результаті досліджень процесів різання, зарізу, стопоріння і удару автогрейдера о перешкоду, що важко долається, була проведена оцінка навантаженості РО [376]. Крім того, було проведено дослідження впливу кута установки відвалу в плані на величину максимального зусилля на кромці ножа відвалу при ударі о перешкоду, що важко долається.

На рис. 1 наведено отриманий нами розрахунковим шляхом графік зміни максимального зусилля $P_{\max }=\max \left(R_{x}\right)$ на кромці ножа відвалу при ударі о перешкоду, що важко долається, в залежності від кута установки відвалу в плані $\alpha$ для трьох категорій грунту.

Апроксимував залежність $P_{\max }=\mathrm{f}(\alpha)$, представлену на рис. 1 , отримаємо:

$$
P_{\max }(\alpha)=A \cdot \sin \left(B \cdot \frac{\alpha-C}{80}\right)+D,
$$

де коефіцієнти $A, B, C$ і $D$, отримані на підставі апроксимації залежності $P_{\max }=\mathrm{f}(\alpha)$, які представлені в табл. 1.

Таблиця 1.

Значення коефіцієнтів A, B, C i D

\begin{tabular}{|c|c|c|c|c|}
\hline $\begin{array}{c}\text { Категорія } \\
\text { грунту }\end{array}$ & $A$ & $B$ & $C$ & $D$ \\
\hline I & 250 & 1,2 & 5 & -10 \\
\hline II & 305 & 1,25 & 10 & 20 \\
\hline III & 380 & 1,4 & 12 & 50 \\
\hline
\end{tabular}




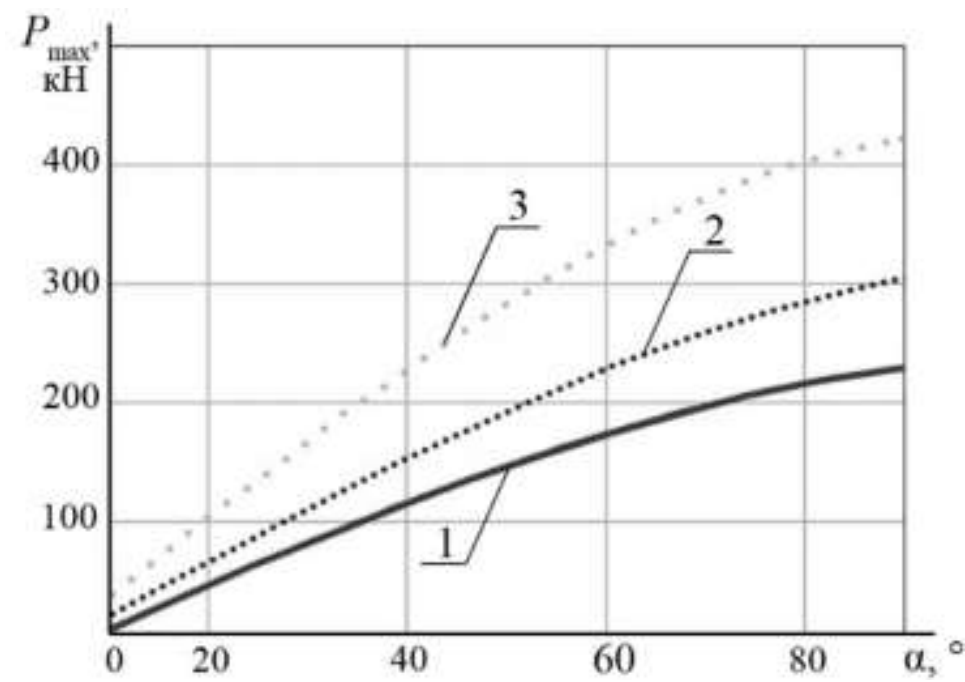

Рисунок 1. Залежність $P_{\max }$ від кута захвату відвалу $\alpha$ :

1 - I категорія грунту, 2 - II категорія, 3 - III категорія.

Згідно з [377] будемо розглядати перші 700 годин роботи ножа в грунті. Тоді залежність зносу ножа автогрейдера як випадкової функції напрацювання в загальному випадку може бути представлена у вигляді $h(t)=a_{u} t^{\beta}+b_{u}$ (рис. 2).

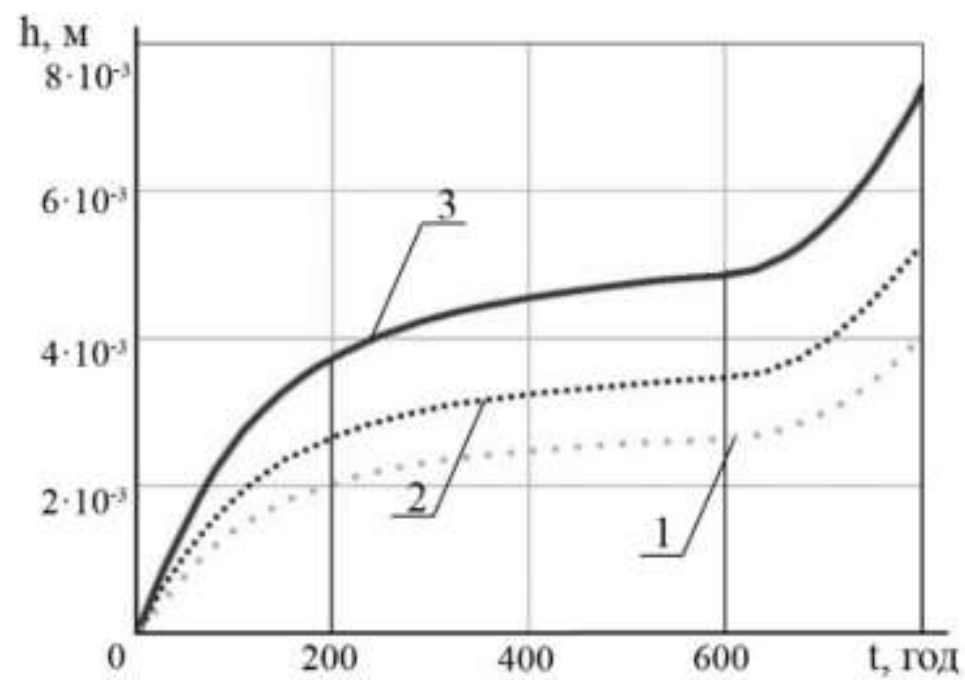

Рисунок 2. Графік залежності величини зносу $h$ від напрацювання $t$ для трьох різних категорій грунту:

1 - I категорія грунту, 2 - II категорія,3 - III категорія. 
У цьому рівнянні при розрахунках були використані статистичні дані, що отримані авторами під час експлуатації автогрейдерів. При цьому було прийнято, що показник $\beta=1 / 2, b_{u}=0$ [375].

3 графіка на рис. 2 видно, що на перших 50-100 годинах роботи знос відбувається інтенсивно і лінійно. Далі знос поступово квазістабілізується, а потім після 500-600 годин починає зростати з більшою швидкістю. Відповідно, швидкість зношування ножа автогрейдера для кожної категорії грунту може бути визначена як $v=d h_{3 н} / d t$ [374].

У рівнянні (1) перший множник, що стосується ймовірності безвідмовної роботи ножа і залежить від максимального навантаження, був перетворений таким чином:

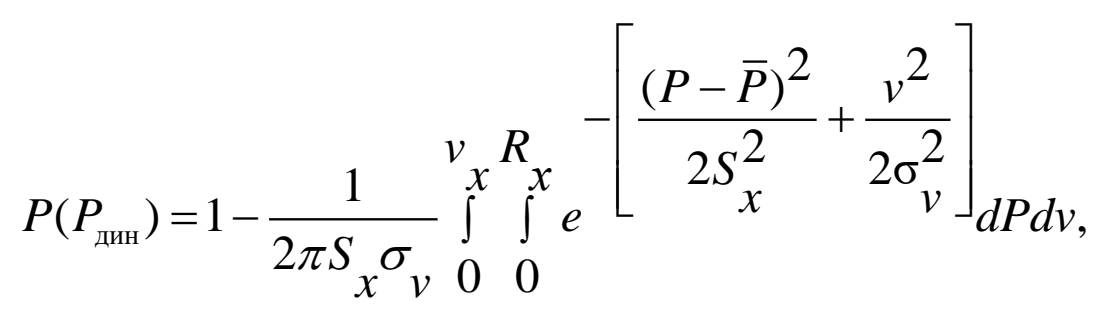

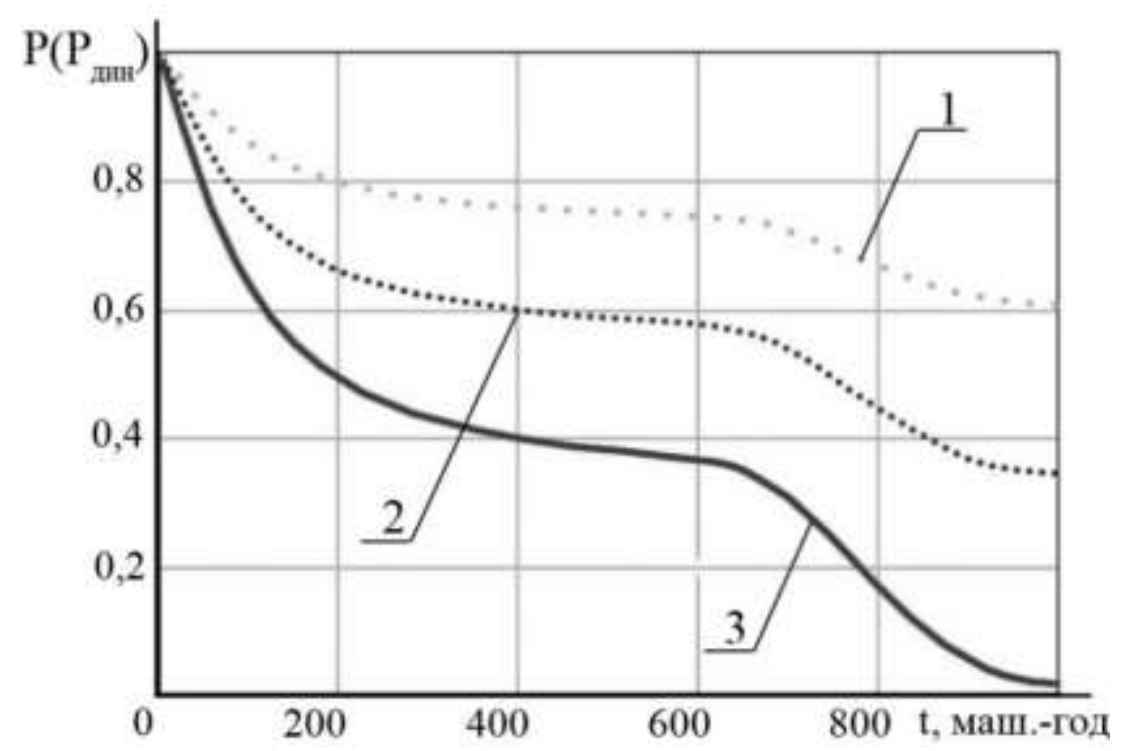

Рисунок 3. Графік зміни ймовірності безвідмовної роботи ножа автогрейдера $P\left(P_{\text {дин }}\right)$ від часу його роботи в абразивному середовищі $t$, год:

1 - I категорія грунту, 2 - II категорія, 3 - III категорія. 
На рис. 3 показано залежності ймовірності безвідмовної роботи ножа автогрейдера $P\left(P_{\text {дин }}\right)$ від часу його експлуатації в абразивному середовищі, які отримані на підставі застосування нормального закону розподілу.

Падаюча характеристика графіків на рис. 3 свідчить про зниження ймовірності безвідмовної роботи ножа $P\left(P_{\text {дин }}\right)$ у процесі експлуатації робочого обладнання автогрейдера.

У результаті апроксимації залежності ймовірності $P\left(P_{\text {дин }}\right)$ від часу роботи ножа в абразивному середовищі $t$ (рис. 3) отримана залежність

$$
P\left(P_{\text {дин }}\right)=1-0,02 \cdot t^{1 / z},
$$

де $z=2,4 ; 2,13 ; 2$ - для I, II і III категорії грунту відповідно.

Виходячи $з$ прийнятих припущень, як було сказано вище, запропоновано розглядати ймовірність безвідмовної роботи як мультиплікативну функцію ймовірностей, кожен аргумент якої залежить від аргументу іншої ймовірності. Тоді сумарна ймовірність безвідмовної роботи ножа автогрейдера становитиме:

$$
P_{\Sigma}=P\left(P_{\text {дин }}\right)\left\{1-\frac{1}{2}\left[\Phi\left[\frac{P_{-1}^{\max }-m\left(P_{-1}\right)}{\sqrt{2 D\left(P_{-1}\right)}}\right]-\Phi\left[\frac{P_{-1}^{\min }-m\left(P_{-1}\right)}{\sqrt{2 D\left(P_{-1}\right)}}\right]\right]\right\}\left\{\Phi\left[\frac{\frac{I_{\text {пр }}}{T^{\beta}}-m\left(a_{u}\right)}{\sqrt{D\left(a_{u}\right)}}\right]\right\},
$$

де $\Phi(x)=\frac{1}{\sqrt{2 \pi}} \int_{0}^{x} e^{-\frac{t^{2}}{2}} d t-$ функція Лапласу,

$P_{-1}=P_{0-1}-R_{x}$

$P_{0-1}-$ несуча здатність при втомному навантаженні;

$R_{x}$ - діюче навантаження на кромку ножа;

$m\left(P_{-1}\right)$ - математичне очікування (середнє значення) межі різниці несучої здатності ножа автогрейдера і максимального навантаження; 
$D\left(P_{-1}\right)$ - середньоквадратичне відхилення межі різниці несучої здатності i максимального навантаження;

У залежності $h(t)=a_{u} t^{\beta}+b_{u}$ розглянемо випадок граничного зносу. Для цього у формулу зносу замість $h(t)$ підставимо значення граничного зносу $I_{\text {гр } \mathrm{i}}$ вирішимо отримане рівняння щодо $t=T$ при $b_{u}=0$. Тоді ресурс ножа буде мати наступний вигляд:

$$
T=\sqrt[\beta]{\frac{I_{\text {гр }}}{a_{u}}},
$$

де $I_{\text {гр }}$ - граничний знос ножа.

На рис. 4 наведено графік-поверхню $P_{\Sigma}=\mathrm{f}\left(P\left(P_{\max }\right), P\left(h_{3 \mathrm{H}}\right)\right)$, побудована 3 використанням залежності (1).

Апроксимуючи залежність сумарної ймовірності безвідмовної роботи робочого обладнання $P_{\Sigma}$ від ймовірностей $P\left(P_{\max }\right)$ i $P\left(h_{3 \mathrm{H}}\right)$, було отримано:

$$
\begin{aligned}
P_{\Sigma}=0,2+1,08 P\left(P_{\max }\right) & +0,24 P\left(h_{3 \mathrm{H}}\right)-0,13 P\left(P_{\max }\right)^{2}-0,08 P\left(h_{3 \mathrm{H}}\right)^{2}+ \\
& +0,846 P\left(P_{\max }\right) P\left(h_{3 \mathrm{H}}\right) .
\end{aligned}
$$

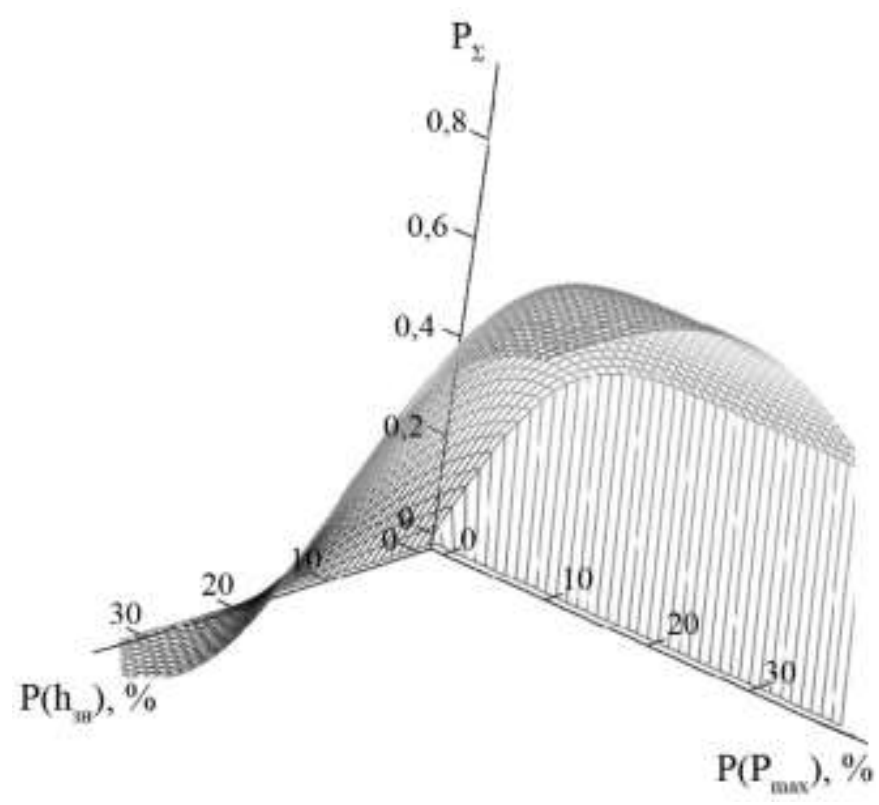

Рисунок 4. Залежність зміни сумарної ймовірності безвідмовної роботи $P_{\Sigma}$ від $P\left(P_{\max }\right)$ и $P\left(h_{3 \mathrm{H}}\right)$. 
Таким чином, отримано залежність ймовірності безвідмовної роботи ножа, до якої увійшли параметри зносу, динамічне і знакозмінне навантаження (рис. 4). Слід також мати на увазі, що рівняння регресії $P_{\Sigma}=\mathrm{f}\left(P\left(P_{\max }\right), P\left(h_{3 н}\right)\right)$ дійсно тільки в межах тих дослідних даних, зокрема, величини зносу, на підставі яких вони отримані. Якщо значення вийдуть за межі дослідних даних, то в цьому випадку прогноз ймовірності безвідмовної роботи ножа може бути отриманий зі значними помилками. Для розширення меж застосування рівнянь їх необхідно будувати на основі даних по декількох або всім сучасним моделям об'єктів одного функціонального призначення. 